\title{
Floor Substrate Preferences of Chickens: A Meta-Analysis
}

\author{
Valerie Monckton, Jennifer L. Ellis and Alexandra Harlander-Matauschek* \\ Department of Animal Biosciences, University of Guelph, Guelph, ON, Canada
}

Environmental enrichment promotes sensory and motor stimulation for species-typical behaviors, which in turn enhance animal well-being. For farmed Galliformes, housing systems often limit enrichment to bedding and litter, that simultaneously act as material for dustbathing and foraging. Therefore, this meta-analysis sought to systematically review and synthesize the substrate preference test literature for Galliformes. Data based on the following four welfare-related behaviors were extracted for analysis: (1) dustbathing, (2) foraging, (3) pecking, and (4) time spent on a given substrate. Literature searches in CAB Direct, Web of Science, and Google Scholar yielded 239 articles, and hand searching yielded an additional five articles. Ten publications that used different chicken strains as test subjects, met the criteria to be included in the systematic review. The effects of bedding type, the number of days birds had access to tested substrates,

OPEN ACCESS

Edited by:

Paul Koene,

Wageningen University and Research, Netherlands

Reviewed by: Manja Zupan Šemrov, University of Ljubljana, Slovenia Lisette M. C. Leliveld, Leibniz Institute for Farm Animal

Biology (FBN), Germany

*Correspondence: Alexandra Harlander-Matauschek aharland@uoguelph.ca

Specialty section: This article was submitted to Animal Behavior and Welfare, a section of the journal Frontiers in Veterinary Science

Received: 16 July 2020 Accepted: 09 November 2020 Published: 09 December 2020

Citation:

Monckton V, Ellis $\mathrm{JL}$ and Harlander-Matauschek A (2020) Floor Substrate Preferences of Chickens: A Meta-Analysis.

Front. Vet. Sci. 7:584162 doi: 10.3389/fvets.2020.584162 enclosure area, and substrate area, on the examined behaviors were determined. We found that birds preferred dustbathing in sand and peat moss more than on any other substrates. The bedding type, size of the enclosure, and size of the substrate area affected the amount of time that birds spent on the tested substrates. When provided the choice between bedding materials, birds spent more time on sand or peat moss than on any other substrate or on no substrate. Notably, most studies did not report relevant physical or chemical characteristics of substrate that may influence birds' preferences, such as grain size, moisture content and the level of soiling. Focusing future studies on identifying substrate characteristics that influence preferences can lead to the discovery of new, practical, enriching beddings that can be easily implemented in housing systems for Galliformes.

Keywords: dustbathing, foraging, bedding, litter, Gallus gallus domesticus, Galliformes, pecking

\section{INTRODUCTION}

Galliformes encompass the largest group of farmed land animals, with chickens alone numbering 23.7 billion in 2018 (1). While many factors affect Galliformes' welfare, bedding is often overlooked and chosen principally based on price and regional availability (2), although other factors such as labor requirements, wear and tear on equipment, cost, accessibility, sustainability, and manure handling and storage may impact bedding choice as well. Yet, while bedding may vary globally, many farmers in Canada and the United States use wood shavings (2, 3). Choice of bedding has been shown to impact many aspects of health and welfare, including the air the birds (and farmers) breathe and the incidence of disease (4-8). Moreover, bedding can act as environmental enrichment-by enhancing "animal welfare through sensory and motor stimulation, using structures and resources that permit the expression of species-typical behaviors 
and promote psychological well-being through physical exercise, manipulative activities, and cognitive challenges according to species-specific characteristics" (9). As a substrate for foraging and dustbathing, bedding can increase Galliformes' behavioral repertoire, and reduce frustrated behaviors. For example, select beddings can reduce the incidence of injurious feather pecking, a repetitive and undesirable behavior common in many breeds of farmed Galliformes (10-12).

Commercial farms commonly use bedding in cage-free systems to absorb moisture from drinkers and birds' excreta, while cage systems may provide bedding in small areas as enrichment for birds to dustbathe and forage in, or beneath cages to absorb moisture from fallen excreta. Whether its primary purpose is moisture absorption or enrichment, bedding is invariably used to both regulate the barn environment and provide environmental enrichment.

To serve both these purposes well, good bedding must first efficiently absorb moisture quickly and facilitate its rapid evaporation, preventing moisture buildup that increases the incidence of disease. Indeed, high bedding moisture has been linked to higher rates of contact dermatitis, respiratory disease, and keratoconjunctivitis $(13,14)$. Moreover, a study by Drake et al. (15) found that the use of bell drinkers (open water) were a risk factor for the development of feather pecking in laying hens, thereby suggesting that moist and caked litter may contribute to adverse health conditions that could spur undesirable behaviors. However, like feather pecking, wet litter substrate is also less loose (friable) and more prone to caking, which makes it an inferior substrate for dustbathing.

Galliformes are motivated to dustbathe $(16,17)$, and will even dustbathe without substrate present (sham dustbathing) (18). Behavioral elements of dustbathing including vertical wing shaking, bill raking and head rubbing, with the goal of incorporating substrate throughout Galliformes' plumage (19). In so doing, it allows birds to remove stale lipids from their feathers $(16,19,20)$ and dislodge ectoparasites $(19,21)$. Furthermore, poor or absent dustbathing substrate can lead Galliformes to become more fearful, leading to higher incidences of feather pecking $(10,22)$.

A combination of pecking and scratching, foraging occupies about $40 \%$ of chickens' daylight hours (23-25). While foraging is used by wild Galliformes as an appetitive behavior to find food, Galliformes will forage even in the presence of readily available feed, suggesting that the behavior itself is motivating $(26,27)$. Consequently, Galliformes' frustrated motivation to forage is strongly related to severe, injurious feather pecking of conspecifics (28), while the provision of high quality pecking substrates is suggested to protect against feather pecking [(29), van Staaveren, et al., submitted] and reduces fearfulness (10), acting as an enrichment. Therefore, providing foraging substrate-one that is nutritive (30) and that requires a longer amount of time to search, manipulate, and consume $(11,28)-$ can also act as enrichment.

First conducted in the 1970s, preference tests investigate where and how animals spend their time when provided different, but similar resources. These results are then used to ascribe preference (31). The preferences demonstrated are then presumed to present conditions that benefit the animals' health and well-being. Many external and internal factors, including animals' previous experiences, the time of day, the animals' mental state, and the differences between the presented options, can impact the outcome of a preference test. It is also important to consider that animals may make decisions that do not align with their welfare, and that their preferences are often restricted by the choices that humans offer them $(31,32)$.

Therefore, this meta-analysis used floor substrate preference studies to assess the bedding material that provided the best enrichment based on where Galliformes spent time, dustbathed, foraged, and pecked. Moreover, it sought to verify claims that peat and sand were preferred dustbathing substrates, and that Galliformes do not have a preference for foraging substrates $(33,34)$. Although bedding type is the focus of this review, many studies included did not distinguish between litter and bedding. Therefore, this review uses the term "substrate" to refer to both bedding (fresh material) and litter (bedding mixed with excreta, feathers and waste feed).

\section{MATERIALS AND METHODS}

\section{Database}

Three primary groups of search terms were used to amass literature. These terms were (1) bedding, litter, or substrate, (2) Galliformes, poultry, fowl, chicken, turkey, or galliform, and (3) preference, motivation, behavior, behavior, forage, foraging, dustbathing, or dust bathing. The search terms were used to hand-search for literature, and to search the following databases: Web of Science (Thomson Reuters Science, New York, NY), CAB Direct (CAB International, Wallingford, UK) and Google Scholar (specified to Animal Welfare and Applied Animal Behavior journals). The search was conducted between January and March 2020, and there were no time period exclusion criteria. The search resulted in 239 related references. The abstracts and titles of all 239 references were examined to determine if they met the five inclusion criteria:

1. Subjects are Galliformes.

2. Study reports at least one of the following: amount of dustbathing (or vertical wing shakes), foraging in, pecking in, or time spent on substrates. Substrate use for nesting purposes is not within the scope of this meta-analysis.

3. Because many countries are moving toward non-cage systems (35), and because substrate has a larger presence in noncage systems, tested substrates must be practical for non-cage systems. In other words, they must be able to absorb moisture, so studies that assessed preference for astroturf, plastic or feed as a bedding were excluded.

4. Study measured the amount of behavior performed as a percentage, count, or time spent. For example, measuring the time spent dustbathing on sand (time spent dustbathing on sand/total time dustbathing). Due to inability to synchronize all data types/units with the information provided, studies that only provided demand curves, or that measured the number of birds performing a behavior could not be used. For example, measuring the percent of birds dustbathing on sand (percent of birds dustbathing on sand/total number of birds). 


\section{Experiment must be set up as a substrate preference test.}

Of the 239 articles found, ten were accessible and met these criteria (Figure 1). All accessible, relevant articles that met criteria used strains of chickens as subjects. One article described the effect of substrate on the behavior of Japanese quail (Coturnix japonica) (36); however, it was excluded as the study was not a preference test. Web Plot Digitizer software (37) was used to extract data from many of these articles that only reported outcomes through graphs. A summary of the database used for this meta-analysis is reported in Table 1. Due to the small number of studies that met the aforementioned criteria, and the diversity of substrates tested, all beddings excluding peat moss, sand and wood were grouped together as "other." This category included a variety of beddings such as straw, paper, feathers, rice hulls, and wheat bran. Since only two studies reported foraging while many reported pecking and scratching (the two behavioral components of foraging), these last two behaviors were combined to represent foraging for all studies. Vertical wing shakes were grouped with dustbathing, as it was used to measure dustbathing in several studies.

All outcomes were converted to percentages of behavior performed on each substrate (time based). Count data was converted as follows:

$$
\begin{aligned}
& \text { Percent of behaviour } x \text { on substrate } y \\
& =\frac{\text { Count of behaviour } x \text { on substrate } y}{\text { Count of behaviour } x \text { on all substrates in study }} \times 100 \text {, }
\end{aligned}
$$

Behavioral time budgets were often broken down as a division of time spent on substrate by behavior (e.g., resting on wood + dustbathing on wood + foraging on wood $=100 \%$ of behaviors on wood). To convert this time budget to a division of a single behavior by substrate (e.g., dustbathing on wood + dustbathing on sand + dustbathing on straw $=100 \%$ of dustbathing), we used the following equation:

$$
\begin{aligned}
& \text { Time doing behaviour } x \text { on substrate } y \\
& =\left(\frac{\text { time doing behaviour } x \text { on substrate } y}{\text { time doing all behaviours on substrate } y}\right) \\
& \times \text { time on substrate } y,
\end{aligned}
$$

followed by an adapted version of Equation (1).

\section{Model Development}

The methodology employed for this meta-analysis is described in St-Pierre (47) and Sauvant et al. (48, 49). Within this approach, study is treated as a random effect, and withinstudy patterns are examined while accounting for sources of between study variance (as the random study effect, or via inclusion of covariates). Data were analyzed using SAS Studio (SAS Inst. Inc., Cary, NC). Relationships between fixed effects were first examined using the Proc Reg MAX R procedure to assess the significance of continuous variables (stocking density, substrate area, enclosure area, number of days with access to substrate, animals $/ \mathrm{m}^{2} /$ day, substrate depth, and grain size) on the outcomes (time spent, dustbathing, foraging, and pecking at substrate). Categorical variables [species (breed), outcome measure (to ensure no effect of measurement)] were manually assessed for significance on outcomes one at a time with bedding type (which was always included regardless of significant outcomes) by running the generalized linear mixed model (GLIMMIX). This preliminary analysis was utilized to advise model development within a GLIMMIX procedure considering the random effect of study. A $P<0.05$ was the criterion for statistical significance and for inclusion of fixed effects in the analysis, while tendencies are reported at $0.05 \leq P \leq 0.1$. The incidence of dustbathing, foraging and pecking on substrate followed a gaussian distribution whereas time spent on substrate followed a lognormal distribution. The cook's D influence analysis was then used with a mixed model to identify influential outliers in the gaussian models, while extreme observations exceeding \pm 3.4 (identified by Proc Univariate) were used to identify outliers in the lognormal model. However, no outliers were removed. The percentage of dustbathing, foraging, and pecking at substrate is shown as LS means \pm SEM, and time spent is shown as omega backtransformed LS means \pm SEM. Wald-type F-statistics were used to test general linear hypotheses, while differences for LS means were tested using $t$-tests. In our description of results, $\mathrm{F}_{\mathrm{v} 1 \text {, } 22}$ denotes a Wald-type F-statistic on $v 1$ numerator and v2 denominator degrees of freedom, and $t_{v}$ denotes a t-statistic on v error degrees of freedom.

\section{Model Evaluation}

Model evaluation was performed to assess model goodness of fit. Models were evaluated based on the normality of residuals, which were examined graphically and using the Shapiro-Wilk statistic. Normality and homogeneity of the random effect was observed graphically with QQ and sample distribution plots, and time spent, the only non-normal model, was evaluated for over dispersion by ensuring that ChiSquare/DF $<1.0$.

Further model evaluations were performed using the studyadjusted Y predicted values. These evaluations employed the use of percent root mean square prediction error (rMSPE\%), which estimates the overall prediction error and identifies the best model as one with a smaller rMSPE\% value. The mean square prediction error (MSPE) is calculated as:

$$
\sum_{i=1}^{n} \frac{\left(O_{i}-P_{i}\right)^{2}}{n}
$$

where $n$ is the total number of observations, $O_{i}$ is the observed value, and $P_{i}$ is the predicted value. The MSPE was then decomposed to determine the model's mean bias (ECT), regression slope deviation (ER) and error from disturbance (random error; ED), as well as the percent of error that each of these make up (50).

Lastly, the model was evaluated using the concordance correlation coefficient (CCC), which identifies a model's relationship as perfectly unrelated $(-1)$, not related $(0)$ or perfectly related (1). The CCC is calculated as:

$$
C C C=R \times C_{b}
$$


where $R$-the Pearson correlation coefficient-measures precision and $C_{b}$ measures accuracy. Precise models display means that are strongly associated to one another, while accurate models have predicted means that are close to observed means. Calculating $C_{b}$ also requires two other variables: $\nu$ and $\mu$. A measure of scale shift, $v$ expresses the change in standard deviation between predicted and observed values. Greater variance in the predicted data compared to observed is shown in a $v$ value larger than one, while values less than one indicate a smaller variance. $\mu$ measures location shift relative to the scale, with negative $\mu$ values implying underprediction and positive values indicating overprediction (51).

\section{RESULTS}

\section{Results of Final Models}

Percent of Time Spent

All independent variables were analyzed for significance in predicting percent of time spent on a substrate. Table 2 presents

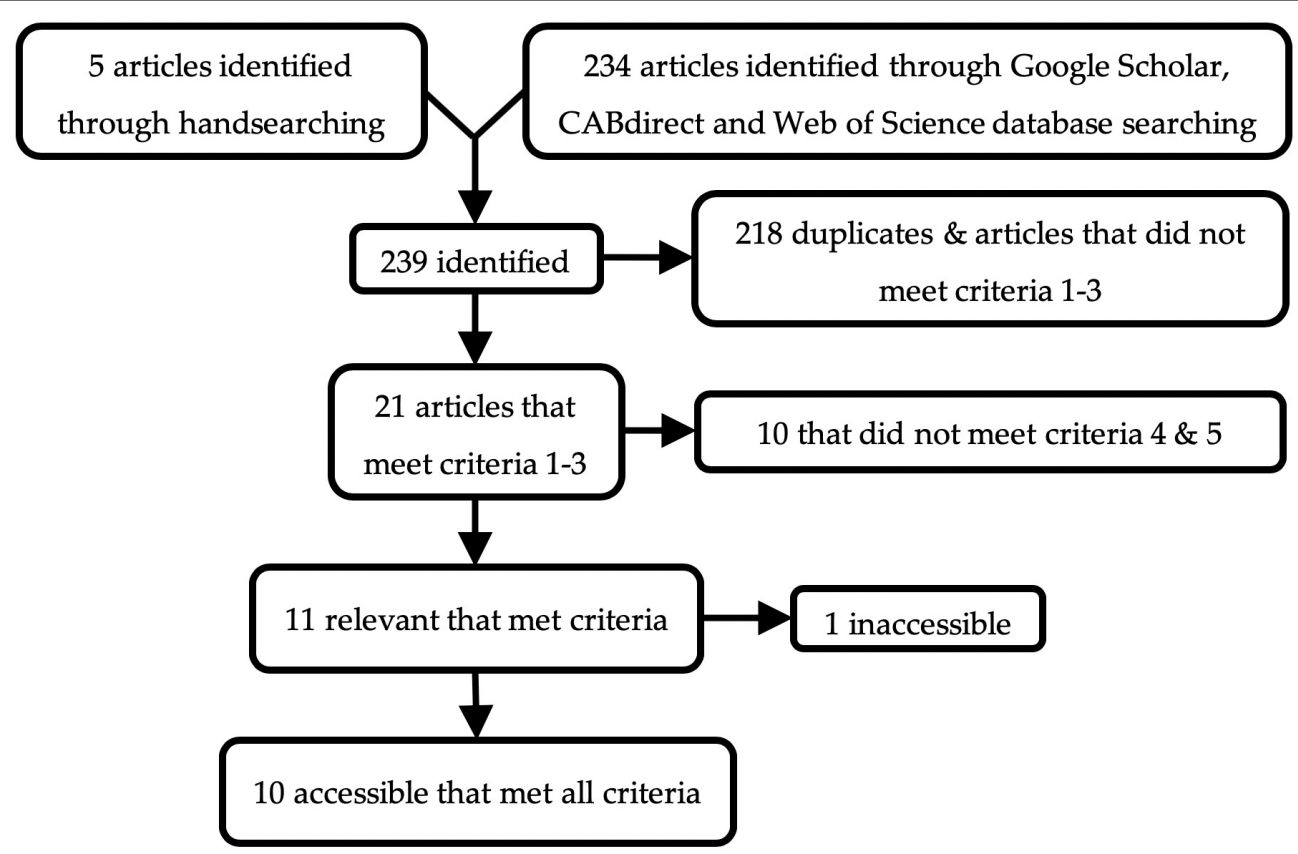

FIGURE 1 | Schematic of the literature search.

TABLE 1 | Database summary.

\begin{tabular}{|c|c|c|c|c|c|c|c|c|c|}
\hline $\begin{array}{l}\text { Publication/Reference } \\
\text { number }\end{array}$ & Study & $\begin{array}{c}\text { Birds } \\
\text { observed }^{\text {a }}\end{array}$ & $\begin{array}{l}\text { Species } \\
\text { (breed) }\end{array}$ & $\begin{array}{c}\text { Days on } \\
\text { substrate }^{b}\end{array}$ & $\begin{array}{l}\text { Enclosure } \\
\text { area }\left(\mathrm{m}^{2}\right)^{\mathrm{c}}\end{array}$ & $\begin{array}{l}\text { Stocking } \\
\text { density }^{d}\end{array}$ & $\begin{array}{l}\text { Animals } / \mathrm{m}^{2} \\
\text { /day }^{\mathrm{e}}\end{array}$ & $\begin{array}{l}\text { Substrate } \\
\text { area }\left(m^{2}\right)^{f}\end{array}$ & $\begin{array}{l}\text { Substrate } \\
\text { depth }(\mathrm{cm})\end{array}$ \\
\hline Jong et al., 2007 (38) & 1 & 16 & Layer & 21.00 & 6.75 & 0.59 & 0.03 & $1.13-2.25$ & 5.0 \\
\hline Sanotra et al., 1995 (39) & 2 & 12 & Layer & 0.04 & 0.41 & 4.94 & 118.52 & $0.03-0.04$ & 4.0 \\
\hline Shields et al., 2004 (40) & 3 & 52 & Broiler & 4.00 & 2.31 & 0.87 & 0.22 & $0.37-0.82$ & 10.0 \\
\hline Villagra et al., 2014 (41) & 4 & 32 & Broiler & 0.05 & 4.00 & 2.00 & 41.14 & 1.00 & 15.0 \\
\hline Shields et al., 2005 (42) & 5 & 60 & Broiler & 49.00 & 9.30 & 1.08 & 0.02 & 4.65 & 2.5 \\
\hline Toghyani et al., 2010 (43) & 6 & 80 & Broiler & 42.00 & 5.76 & 3.47 & 0.08 & 1.44 & 2.0 \\
\hline van Liere et al., 1990 (44) & 7 & 23 & Layer & 5.00 & 3.90 & 1.54 & 0.31 & 0.36 & 12.0 \\
\hline $\begin{array}{l}\text { Hogan and Vestergaard, } \\
1992 \text { (45) }\end{array}$ & 8 & 10 & Jungle Fowl & 0.02 & 0.48 & 4.17 & 171.43 & 0.12 & 2.0 \\
\hline $\begin{array}{l}\text { Petherick and Duncan, } \\
1989 \text { (46) }\end{array}$ & 9 & 48 & Layer & 0.02 & 5.76 & 1.04 & 50.00 & 0.13 & 4.0 \\
\hline $\begin{array}{l}\text { Guinebretière et al., } 2014 \\
\text { (33) }\end{array}$ & 10 & 60 & Layer & 4.00 & 1.05 & 3.81 & 0.95 & 0.49 & 3.0 \\
\hline
\end{tabular}

${ }^{a}$ Total number of birds observed in each study (some studies picked focal birds).

${ }^{b}$ Number of days birds were allowed access to tested substrates (in enclosure area). Small numbers represent studies that moved animals into a separate area to observe.

${ }^{c}$ The size of the total enclosure, encompassing all substrate areas, in $\mathrm{m}^{2}$.

${ }^{d}$ Animals per $\mathrm{m}^{2}$; Stocking density = animals per group (not shown; some studies used focal birds) $\div$ enclosure area $\left(\mathrm{m}^{2}\right)$.

eproxy for degree of substrate soiling (higher numbers indicate more soiling); animals $/ \mathrm{m}^{2} /$ day $=$ stocking density $\div$ days on substrate.

${ }^{f}$ The area $\left(\mathrm{m}^{2}\right)$ occupied by one substrate within the enclosure. 
TABLE 1 | (continued)

\begin{tabular}{|c|c|c|c|c|c|c|c|c|c|c|c|}
\hline Study & Outcome measure ${ }^{a}$ & \multicolumn{5}{|c|}{ Substrates tested } & \multicolumn{5}{|c|}{ Outcomes reported } \\
\hline 2 & Time budget & & $\checkmark$ & $\checkmark$ & $\checkmark$ & & & $\checkmark$ & & $\checkmark$ & $\checkmark$ \\
\hline 3 & Count & & $\checkmark$ & & $\checkmark$ & $\checkmark$ & $\checkmark$ & $\checkmark$ & & $\checkmark$ & \\
\hline 4 & Time budget & & $\checkmark$ & $\checkmark$ & $\checkmark$ & & $\checkmark$ & $\checkmark$ & & $\checkmark$ & $\checkmark$ \\
\hline 7 & Count & & $\checkmark$ & $\checkmark$ & & & & $\checkmark$ & & & \\
\hline 8 & Percent & & $\checkmark$ & $\checkmark$ & & & & $\checkmark$ & & $\checkmark$ & \\
\hline 9 & Count & $\checkmark$ & $\checkmark$ & $\checkmark$ & & & & $\checkmark$ & & $\checkmark$ & $\checkmark$ \\
\hline 10 & Count & $\checkmark$ & $\checkmark$ & & $\checkmark$ & & & $\checkmark$ & & $\checkmark$ & $\checkmark$ \\
\hline
\end{tabular}

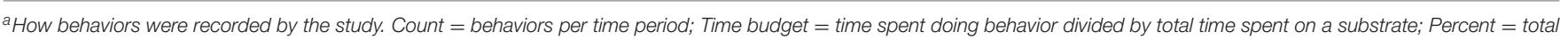
time spent doing a behavior divided by substrate.

${ }^{b}$ Other substrates include: straw, feathers, recycled paper, rice hulls, and wheat bran.

${ }^{c}$ Foraging $=$ (percent of pecking + percent of scratching $) \div 2$.

${ }^{d}$ Scratching was not reported without pecking. Therefore, it was combined to make foraging, and is not analyzed alone.

TABLE 2 | The significance of independent variables on outcomes.

Independent variables
Models

\begin{tabular}{|c|c|c|c|}
\hline \multicolumn{4}{|c|}{ Models } \\
\hline Time spent & Dustbathing & Foraging & Pecking \\
\hline * & & & \\
\hline$\star$ & - & & \\
\hline & & 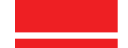 & \\
\hline & 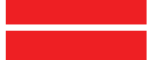 & 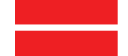 & 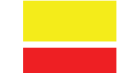 \\
\hline & & & 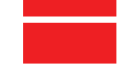 \\
\hline & & L & 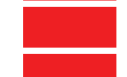 \\
\hline & & & \\
\hline
\end{tabular}

Bedding type

Substrate area

Enclosure area

Number of days birds were allowed access to tested substrates

Stocking density

Animals $/ \mathrm{m}^{2} /$ day

Species (breed)

Substrate depth

Grain size

Green indicates a significant effect $(P<0.05)$, yellow indicates a tendency $(0.05 \leq P \leq 0.1)$, and red indicates a non-significant effect $(P>0.1)$. Starred (*) variables were included in model equations.

a summary of variables' effects on time spent. Bedding type $\left[F_{(4,10)}=11.82, P=0.0008\right]$, substrate area $\left[F_{(1,10)}=39.18\right.$, $P<0.0001]$, and enclosure area $\left[F_{(1,10)}=8.89, P=0.0138\right]$ all significantly affected which substrate chickens preferred spending their time on Figure 2. Birds spent more time on sand $(41 \pm 33.6 \%)$ than on wood $\left[23 \pm 18.6 \% ; t_{(10)}=3.47\right.$, $P=0.0376]$, other substrates $\left[17 \pm 13.8 \% ; t_{(10)}=5.09\right.$, $P=0.0033]$, and no substrate $\left[9 \pm 8.0 \% ; t_{(10)}=5.58, P=0.0017\right]$. Additionally, birds spent more time on peat moss $(35 \pm 31.5 \%)$ than on no substrate $\left[t_{(10)}=3.67, P=0.0280\right]$. However, there was no significant difference between the amount of time chickens spent on peat moss, wood and other substrates ( $p$ $>0.05$ ). Table 3 shows the predictive equations produced for time spent on floor substrates if all substrates are given at the same time.

\section{Percent of Dustbathing}

All independent variables were analyzed for significance in predicting percent of dustbathing. Table 2 presents a summary of variables' effects on dustbathing. Bedding type $\left[F_{(3,30)}=8.98\right.$, $P=0.0002]$ alone significantly affected substrate preference for dustbathing (Figure 3). Chickens dustbathed significantly more on peat moss $(79 \pm 16.3 \%)$ than on wood $\left[16 \pm 8.3 \% ; t_{(30)}=3.51\right.$, $P=0.0074]$ and other substrates $\left(9 \pm 8.3 \% ; t_{(30)}=3.87\right.$, $P=0.0029]$. Chickens dustbathed more on sand $(50 \pm 7.5 \%)$ than on wood $\left[t_{(30)}=3.21, P=0.0158\right]$ and other substrates $\left[t_{(30)}=3.85, P=0.0031\right]$. Percent of dustbathing was similar between peat moss and sand. Because bedding is the only variable that impacts the percent of dustbathing, the equations produced by this model are identical to the LS means \pm SEM presented in Figure 3, and are therefore not shown. 


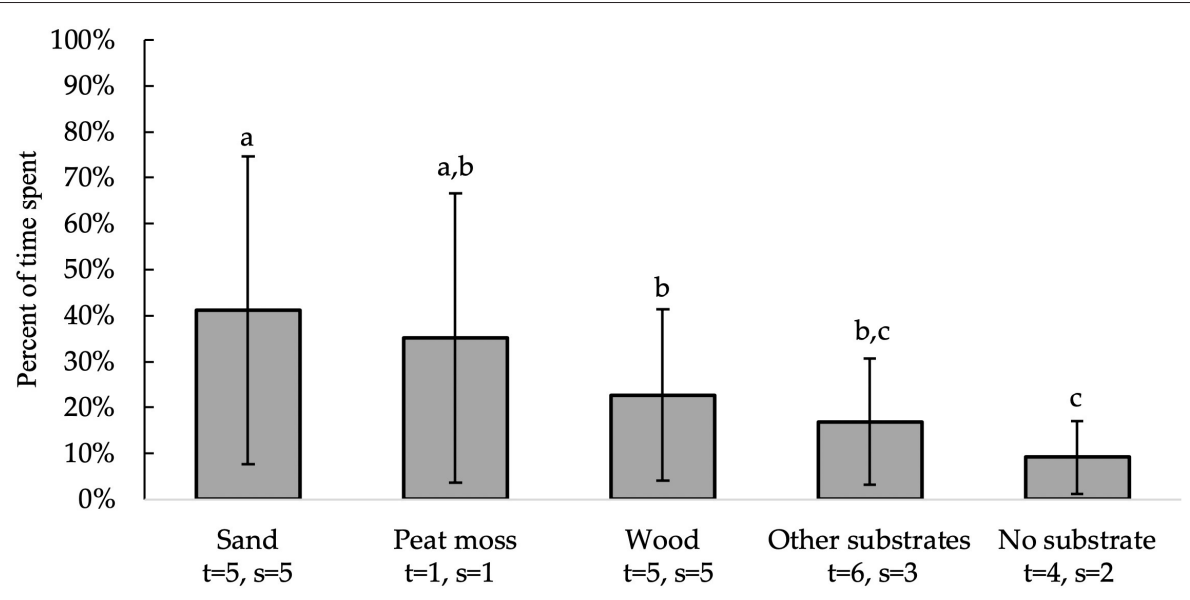

FIGURE 2 | Percent of time spent (LS means \pm SEM) on substrates (sand, peat moss, wood, other substrates and no substrate). Different letters indicate significant differences $(P<0.05)$. Number of treatments $(t)$ and studies $(s)$ that include each substrate are noted below each bar. The numbers of $t$ and $s$ differ because some studies used multiple floor substrates of the same kind with distinct differences (e.g., wire floors and a concrete "home" area for no substrate).

TABLE 3 | Equations for time spent.

\begin{tabular}{ll}
\hline Percent of time spent on: & Equation $^{\mathbf{a}}$ \\
\hline Sand & $=1.3( \pm 0.17)+2.0( \pm 0.32) \times$ Substrate area $\left(\mathrm{m}^{2}\right)-1.0( \pm 0.34) \times$ Enclosure area $\left(\mathrm{m}^{2}\right)$ \\
Peat moss & $=1.1( \pm 0.33)+2.0( \pm 0.32) \times$ Substrate area $\left(\mathrm{m}^{2}\right)-1.0( \pm 0.34) \times$ Enclosure area $\left(\mathrm{m}^{2}\right)$ \\
Wood & $=0.7( \pm 1.84)+2.0( \pm 0.32) \times$ Substrate area $\left(\mathrm{m}^{2}\right)-1.0( \pm 0.34) \times$ Enclosure area $\left(\mathrm{m}^{2}\right)$ \\
Other substrates & $=0.4( \pm 0.18)+2.0( \pm 0.32) \times$ Substrate area $\left(\mathrm{m}^{2}\right)-1.0( \pm 0.34) \times$ Enclosure area $\left(\mathrm{m}^{2}\right)$ \\
No substrate & $=-0.2( \pm 0.27)+2.0( \pm 0.32) \times$ Substrate area $\left(\mathrm{m}^{2}\right)-1.0( \pm 0.34) \times$ Enclosure area $\left(\mathrm{m}^{2}\right)$
\end{tabular}

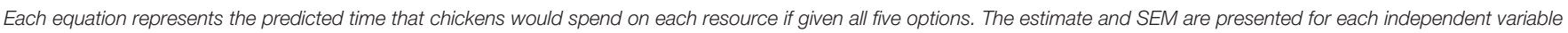
in the equation.

${ }^{a}$ The output of all equations must be backtransformed from a lognormal distribution to obtain the result on the original data scale (e equation).

\section{Percent of Foraging}

All independent variables were analyzed for significance in predicting percent of foraging. Table 2 presents a summary of variables' effects on foraging. None of the analyzed variables, including bedding type $\left[F_{(3,21)}=80.73, P=0.5430\right]$, significantly affected substrate preference for foraging behavior (Figure 4). Birds spent equal percentages of time foraging on peat moss, sand, wood and other substrates. Furthermore, analysis of the residuals vs. other factors revealed that none of the independent variables significantly affected the accuracy of model predictions (data not shown).

\section{Percent of Pecking}

All independent variables were analyzed for significance in predicting percent of pecking. Table 2 presents a summary of variables' effects on pecking. Similar to foraging, none of the analyzed variables, including bedding type $\left[F_{(3,22)}=1.30\right.$, $P=0.3002]$, significantly affected substrate preference for pecking behavior at substrate (Figure 5). However, the number of days birds were allowed access to each tested substrate impacted the percentage of pecking $(0.05 \leq P \leq 0.1)$. Further analysis of the residual vs. other factors revealed similar results to foraging. However, plotting the residual vs. the number of

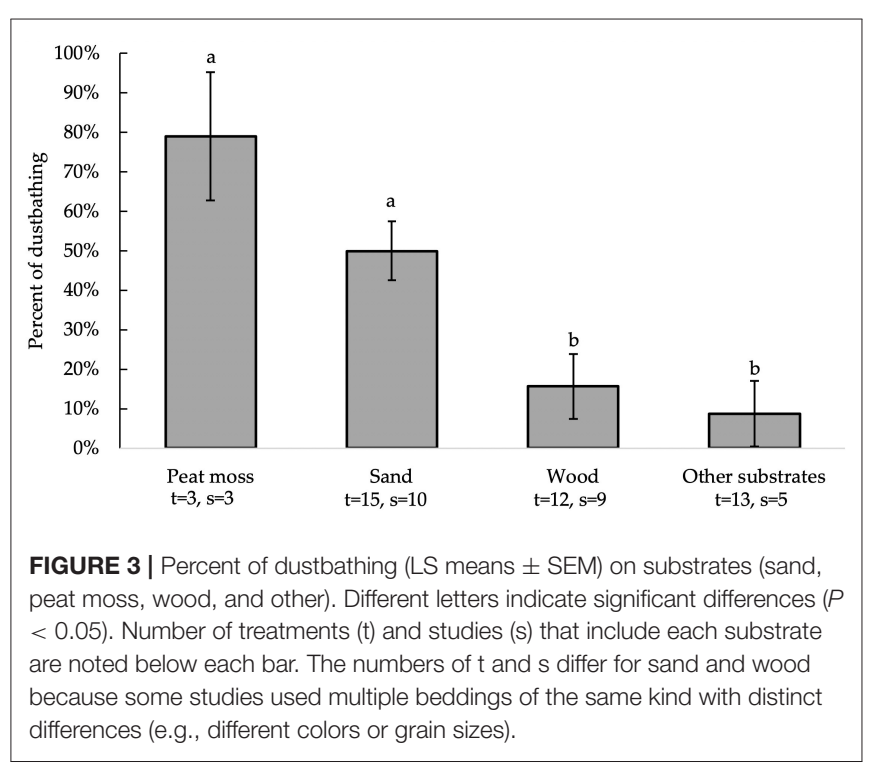

days birds were allowed access to each tested substrate (Figure 6) showed a non-constant distribution of residuals across days on substrate. One study in particular (42) influenced the model 


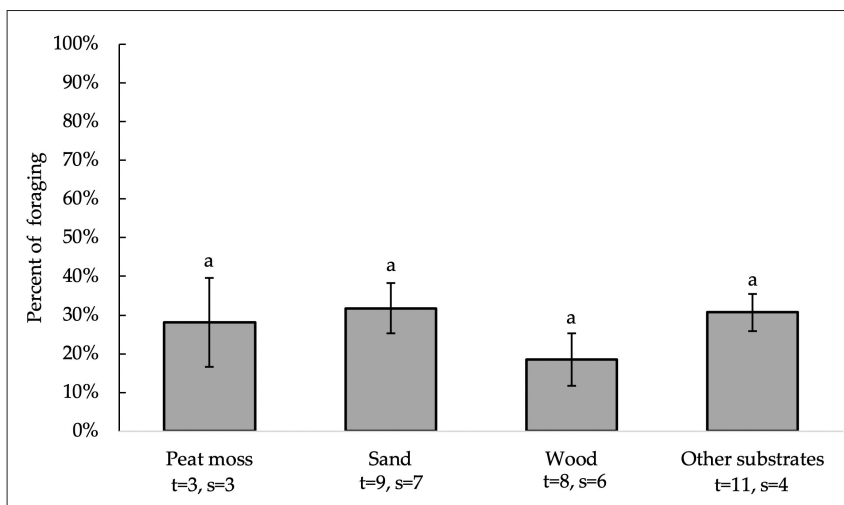

FIGURE 4 | Percent of foraging (LS means \pm SEM) on substrates (sand, peat moss, wood, and other). Different letters indicate significant differences $(P<$ 0.05). Number of treatments ( $t$ ) and studies (s) that include each substrate are noted below each bar. The numbers of $t$ and $s$ differ for sand and wood because some studies used multiple beddings of the same kind with distinct differences (e.g., different colors or grain sizes).

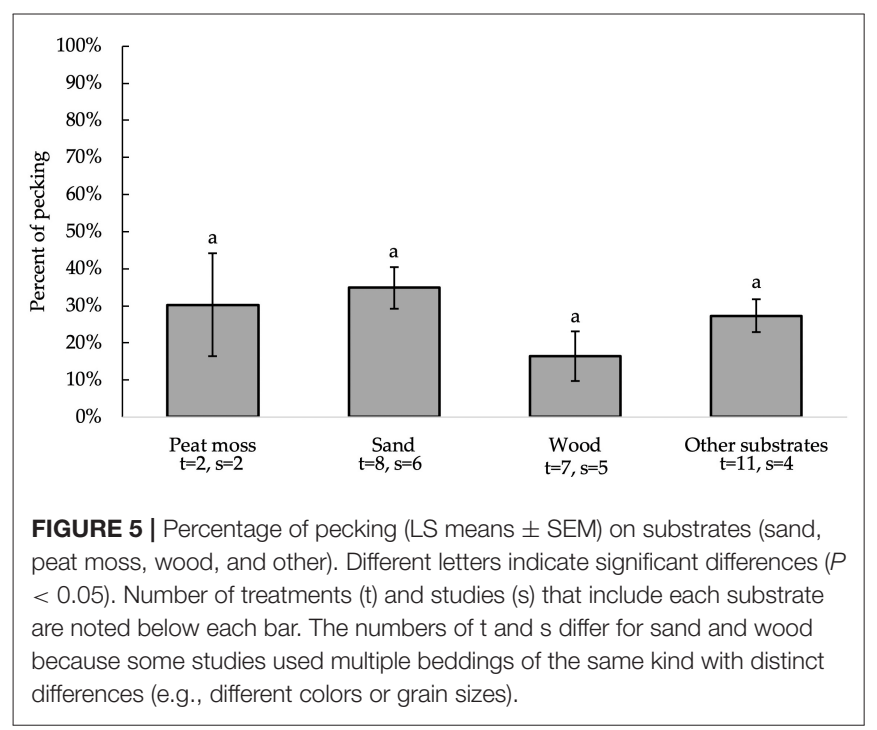

to over-predict higher values, which decreased the pecking model's accuracy.

\section{Model Evaluation}

Model evaluation statistics based on the study-adjusted $Y$ values for each of the final models are presented in Table 4. These results provide a metric of each model's ability to predict the identified outcome, and how well the model described the observed variation (be it due to fixed or random effects). Results indicate that, given its high CCC, the time spent model has both high accuracy $\left(\mathrm{C}_{\mathrm{b}}\right)$ and precision $(\mathrm{R})$, describing the data well. However, the breakdown of rMSPE\% shows that almost $10 \%$ of error is due to regression (ER\%). Evaluation of the observed vs. adjusted predicted values shows that this error due to regression is driven entirely by observations of no substrate. Given the variety in what may be considered "no substrate" (e.g., wire

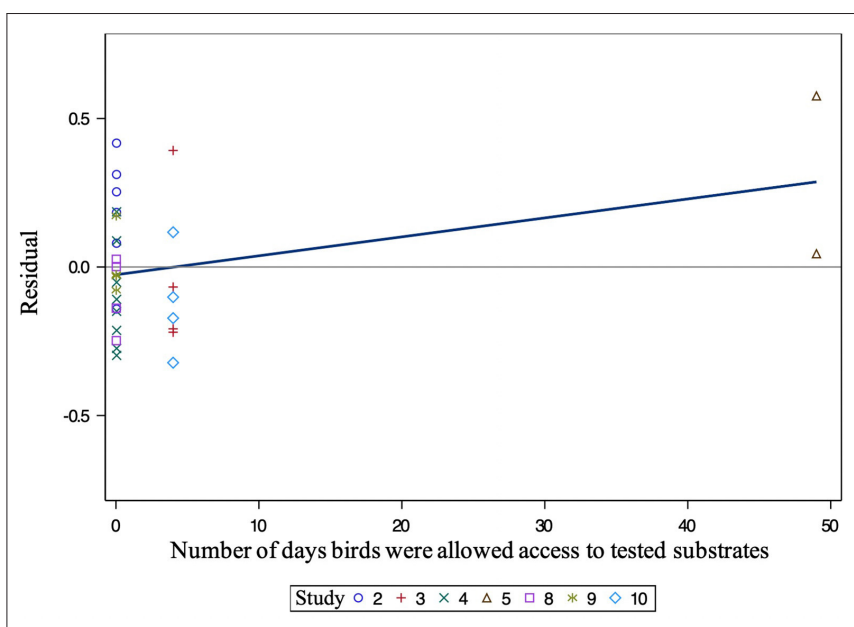

FIGURE 6 | Residual of pecking vs. the number of days birds were allowed access to tested substrates. Different symbols indicate different studies. All numbers correspond to a study (Table 1).

TABLE 4 | Final model evaluation parameters by outcome (time spent, dustbathing, foraging, pecking).

\begin{tabular}{lcccc}
\hline & Time spent & Dustbathing & Foraging $^{\text {a }}$ & Pecking $^{\mathbf{b}}$ \\
\hline rMSPE\% $^{c}$ & 21.1597 & 84.1658 & 73.9937 & 78.0356 \\
ECT\% $^{\mathrm{d}}$ & 0.0541 & 0.0000 & 0.0000 & 0.0000 \\
ER\% $^{\mathrm{C}}$ & 9.4228 & 0.3797 & 14.2886 & 14.5253 \\
ED\% $^{\mathrm{f}}$ & 90.5232 & 99.6203 & 85.7114 & 85.4747 \\
CCC $^{\mathrm{a}}$ & 0.9410 & 0.6000 & 0.0168 & 0.0887 \\
$\mathrm{R}^{\mathrm{h}}$ & 0.9421 & 0.6686 & 0.0231 & 0.1085 \\
$\mathrm{C}_{\mathrm{b}}$ & 0.9988 & 0.8974 & 0.7272 & 0.8171 \\
\hline
\end{tabular}

${ }^{a, b}$ Non-significant equations.

${ }^{c}$ Root means squared prediction error, \% of mean.

${ }^{d}$ Error due to mean bias; \% of total MSPE.

e Error due to regression; \% of total MSPE.

${ }^{f}$ Error due to disturbance; \% of total MSPE.

${ }^{g}$ Concordance correlation coefficient; $\mathrm{C}=\mathrm{R} \times \mathrm{Cb}$.

${ }^{h}$ Pearson correlation coefficient; measure of precision.

flooring, a home compartment with feed and water etc.), this discrepancy between observed and predicted outcomes in the "no substrate" category makes sense.

Conversely, the distribution of $\mathrm{rMSPE} \%$ in dustbathing is mostly weighted onto random error. However, despite this expected, preferred distribution of error, the CCC of dustbathing is relatively low. This may be because, while the model shows good accuracy, it also has a relatively low precision (R), implying that a great deal of random error is yet to be accounted for. Similarly, the foraging and pecking models showed good accuracy but very low precision, which is unsurprising given that both of these models are non-significant.

\section{DISCUSSION}

The meta-analysis presented herein systematically reviewed chickens' preferences for substrates based on the time spent on a given substrate, as well as dustbathing, foraging, and pecking 
behaviors on the substrate. While the search criteria for the meta-analysis included Galliformes, the eligible studies, in the end, only included chickens (laying hens, broilers, or red jungle fowl) as test subjects. The effect of substrates on the behavior and preferences of other commercially farmed Galliformes such as pheasants, guinea fowl, Japanese quail, bobwhite quail, and turkeys is therefore unknown. Nevertheless, the stimulating and motivating qualities of substrates for dustbathing, pecking, and foraging is expected to be similar, if not the same, for other commercially relevant Galliformes (36, 52-54).

We found that bedding type, substrate area and the enclosure area influenced where chickens chose to spend their time. Birds spent more time on areas with sand than on those with wood, other substrates, or no substrate. Interestingly, the time spent on peat moss was similar to all other substrates tested, although they spent more time on peat moss than on no substrate. These findings suggest that chickens may decide where they spend time based on the comfort and feel of the substrate. For example, compared to peat moss and sand, many wood shavings contain chemical irritants $(55,56)$ in addition to being physically abrasive. Therefore, it is likely that, when provided with an alternative, birds avoided physically uncomfortable beddings like wood. This would be particularly relevant for heavier birds like broiler chickens and turkeys that have reduced perching ability (57) and spend much of their time sitting or lying down (58). It is, however, important to note that few studies have examined the impact of various substrates on comfort behaviors [e.g., preening, stretching, etc.; $(42,43)]$. The time spent on a substrate also correlated positively with amount of space it covered, with chickens spending more time on substrates that covered larger areas (Table 2). Given that many chickens like to explore, the positive effect of a larger substrate area was likely counterbalanced when the enclosure areas were also large, as birds tended to spend less time on any given substrate with increasing enclosure space.

It is, however, important to note that only five studies reported the amount of time spent on each tested substrate. Moreover, model evaluation revealed that, despite the model's high accuracy and precision, it had a high error due to regression likely caused by observations of no substrate. As such, the equations produced from the percent of time spent model should be taken with caution. Additionally, even though only one study reported time spent with peat moss, it was analyzed as a separate substrate due to its reputation as a preferred bedding $(33,34,59)$. Thus, conclusions for peat moss based on this analysis, while interesting, should also be approached with caution.

We report that chickens' dustbathing preferences were only influenced by the bedding type. Birds dustbathed on peat moss and sand significantly more than on wood and other substrates. Since peat moss and sand look and feel like dirt: the natural dustbathing substrate for Galliformes, the birds may find the naturalness of these beddings appealing. Galliformes are also known to prefer dustbathing in substrates with low lipid content $(20,60)$ that are easily distributed throughout the plumage (friable and of small grain size (30)). It follows then that they would choose beddings that readily absorb lipids from plumage $(16,44)$ and that are less prone to caking. However, only three studies tested dustbathing preference for peat moss, while 10 studies used sand, making conclusions about chickens' preference for peat moss less robust than the findings for sand.

Bedding type did not influence chickens' preference for foraging or pecking at substrates. Moreover, unlike dustbathing and time spent on a substrate, chickens did not show a substrate preference to forage or peck in. Given that foraging and pecking are frequently performed, exploratory behaviors (23-25), studies may require greater contrast in bedding type to see preference for foraging or pecking. For example, offering birds the choice between highly palatable, nutritive substrates compared to inorganic, non-nutritive substrates (30). The number of days birds could access each tested substrate tended to affect the frequency of substrate pecking (Figure 6). Increasing the number of days exposed to substrates caused the model to over-predict, decreasing the accuracy of the pecking model. This overprediction was largely driven by one study (42) that exposed birds to the same substrate for 49 days, whereas other studies that reported pecking exposed birds to tested substrates for 5 days or less. Therefore, proper understanding of the effect of the number of days birds were allowed access to tested substrates requires that more research examine pecking behavior on substrate over longer periods of time.

Most studies did not explicitly state if litter was cleaned out or if fresh bedding was ever applied on top of litter, making the true number of days birds were allowed access to tested substrates an estimated variable. Nevertheless, the proxy variable for cleanliness, animals per $\mathrm{m}^{2}$ per day, did not significantly affect any of the behaviors analyzed. With regards to foraging and pecking behavior, chickens are known to forage in and consume excreta in the absence of substrates $(61,62)$, and are reported to consume $5-24 \%$ of their group's excreta even when housed on bedding (63). Therefore, substrates may become equally attractive foraging and pecking material as they soil. Moreover, soiled bedding degrades to a soil-like consistency over time, and a study by Moesta et al. (64) found that soiled, degraded wood shavings were more stimulating and adequate for dustbathing compared to fresh wood shavings. The data presented here, in addition to the literature, would therefore support the idea that degree of soiling has little impact on the behaviors quantified in this meta-analysis.

In general, substrate characteristics are under-studied or inconsistently reported in the current literature. For example, only three of the 10 studies in this meta-analysis reported grain size of select substrates. Of these studies, none reported grain size for all substrates included in the preference test and five grain sizes reported were ranges. While every study reported dustbathing or its various behavioral elements, none reported caking which severely impact behavioral activities, including dustbathing. Other measures that might influence dustbathing, such as moisture content, analogous measurements for degree of substrate friability, or lipid content were all lacking from the examined studies, and may have contributed to the low precision of the dustbathing model. Reporting measurable or observable substrate characteristics that may influence Galliformes' preferences can contribute to understanding reported observations, improve study reproducibility (65), and 
applicability across species. Despite chickens' preference for sand and peat moss, farmers are reticent to their use due to labor requirements, wear and tear on equipment, cost, accessibility and unsustainability. Therefore, knowledge of important substrate qualities for dustbathing, foraging, and other high priority behaviors (19) can aid in the search for practical, cost-effective, sustainable, healthy, and enriching substrates. For example, knowledge of chickens' preference for low lipid content substrates for dustbathing and nutritive substrates for foraging led Guinebretiere et al. (33) to test laying hens' preference for wheat bran (evaluated in this meta-analysis under "other substrates") compared to peat moss and sand. Refocussing on substrate characteristics may also reduce the number of animals used for substrate preference research, thereby satisfying one of the " 3 Rs (Reduce, Replace, Refine)" of non-human animal research (66). Specifically, evaluations of substrate characteristics instead of, or before, performing multiple preference tests with different species of Galliformes could be used in the place of many exploratory preference tests using new substrates.

Finally, this meta-analysis also highlighted the need for consistent methods of measurement. For instance, all studies measured dustbathing, but this behavior was measured using six different observations: vertical wing shakes per hour, percent of vertical wing shakes, mean dust-baths per hen per day, mean total dust-baths, dust-baths per hour, and percent of time (on substrate) spent dustbathing. This variation in measurement methods and the lack of reported SEM prevented weighting studies by SEM.

\section{CONCLUSIONS}

As the first meta-analysis of chickens' floor substrate preferences, this review confirmed that chickens preferred to dustbathe and generally spend time on sand and peat moss over wood shavings, other substrates and no substrate. However, only 30\% of the studies used in the analysis examined preference for peat moss,

\section{REFERENCES}

1. Statista Statistics Portal. Number of chickens worldwide from 1990 to 2018. (2020). Available online at: https://www.statista.com/statistics/263962/ number-of-chickens-worldwide-since-1990/ (accessed April 23, 2020).

2. Ritz CW, Fairchild BD, Lacy MP. Litter Quality and Broiler Performance (2009) Athens, GA: University of Georgia.

3. van Staaveren N, Leishman EM, Adams SM, Wood BJ, Harlander-Matauschek A, Baes CF. Housing and management of Turkey flocks in Canada. Animals. (2020) 10:1159. doi: 10.3390/ani10071159

4. Miles D, Rowe D, Cathcart T. High litter moisture content suppresses litter ammonia volatilization. Poultry Sci. (2011) 90:1397-405. doi: 10.3382/ps.2010-01114

5. Miles D, Rowe D, Cathcart T. Litter ammonia generation: moisture content and organic versus inorganic bedding materials. Poultry Sci. (2011) 90:11629. doi: 10.3382/ps.2010-01113

6. Bilgili SF, Hess JB, Blake JP, Macklin KS, Saenmahayak B, Sibley JL. Influence of bedding material on footpad dermatitis in broiler chickens. J Appl Poultry Res. (2009) 18:583-9. doi: 10.3382/japr.2009-00023

7. Mayne R, Else R, Hocking P. High litter moisture alone is sufficient to cause footpad dermatitis in growing turkeys. suggesting that the data related to peat moss are less robust than those of sand. We also report that the bedding type, enclosure area and substrate area affected the time that birds spent on the tested substrates. Interestingly, none of the examined variables affected foraging and pecking behavior.

We noted that few studies reported physical and chemical properties of substrates, which, in the future, can be used to develop and discover novel beddings. Moreover, variations in data reporting and the lack of reporting standard error of the mean limited analysis.

\section{DATA AVAILABILITY STATEMENT}

The raw data supporting the conclusions of this article will be made available by the authors, without undue reservation.

\section{AUTHOR CONTRIBUTIONS}

VM, JE, and AH-M conceived and designed the study. JE provided statistical analysis support. VM analyzed the data and wrote the main manuscript. All authors reviewed and approved the final manuscript.

\section{FUNDING}

VM received support from the Resource Allocation for Graduates (RAG) Scholarship from the University of Guelph Department of Animal Biosciences. JE would like to acknowledge the support of the Natural Sciences and Engineering Research Council of Canada (NSERC), (\#04985). Additionally, AH-M also received funding from NSERC (Discovery Grant \#400983).

\section{ACKNOWLEDGMENTS}

The authors would like to thank Dr. Michelle Edwards for her additional support in statistical analysis.

\section{Br Poultry Sci. (2007) 48:538-45. doi: 10.1080/000716607015 73045}

8. Shepherd EM, Fairchild BD, Ritz CW. Alternative bedding materials and litter depth impact litter moisture and footpad dermatitis. J Appl Poultry Res. (2017) 26:518-28. doi: 10.3382/japr/pfx024

9. National Research Council. Guide for the Care and Use of Laboratory Animals. 8th ed. Washington, DC: National Academies Press (2011).

10. Huber-Eicher B, Wechsler B. Feather pecking in domestic chicks: its relation to dustbathing and foraging. Anim Behav. (1997) 54:75768. doi: 10.1006/anbe.1996.0506

11. Huber-Eicher B, Wechsler B. The effect of quality and availability of foraging materials on feather pecking in laying hen chicks. Anim Behav. (1998) 55:86173. doi: 10.1006/anbe.1997.0715

12. Erasmus MA. Welfare issues in turkey production. In: Mench JA, editor. Advances in Poultry Welfare. Cambridge, MA: Woodhead Publishing (2018). p. 263-91. doi: 10.1016/B978-0-08-100915-4.00 013-0

13. Wu K, Hocking PM. Turkeys are equally susceptible to foot pad dermatitis from 1 to 10 weeks of age and foot pad scores were minimized when litter moisture was less than 30\%. Poultry Sci. (2011) 90:11708. doi: 10.3382/ps.2010-01202 
14. Kristensen $\mathrm{HH}$, Wathes C. Ammonia and poultry welfare: a review. World's Poultry Sci J. (2000) 56:235-45. doi: 10.1079/WPS20000018

15. Drake KA, Donnelly CA, Dawkins MS. Influence of rearing and lay risk factors on propensity for feather damage in laying hens. Br Poult Sci. (2010). 51:725-33. doi: 10.1080/00071668.2010.528751

16. van Liere DW. The significance of fowls' bathing in dust. Anim Welf. (1992) 1:187-202.

17. Widowski TM, Duncan IJH. Working for a dustbath: are hens increasing pleasure rather than reducing suffering? Appl Anim Behav Sci. (2000) 68:3953. doi: 10.1016/S0168-1591(00)00088-5

18. Olsson IAS, Keeling LJ, Duncan IJH. Why do hens sham dustbathe when they have litter? Appl Anim Behav Sci. (2002) 76:53-64. doi: 10.1016/S0168-1591(01)00181-2

19. Van Rooijen J. Dust bathing and other comfort behaviours of domestic hens. In: Martin G, Sambraus HH, Steiger C, editors. Das Wohlergehen von Legehennen in Europa-Berichte, Analysen und Schlussfolgerungen. Wageningen: Internationale Gesellschaft für Nutztierhaltung IGN; Verlag Universität Kassel (2005). p. 110-23.

20. Scholz B, Kjaer J, Urselmans S, Schrader L. Litter lipid content affects dustbathing behavior in laying hens. Poultry Science. (2011) 90:24339. doi: $10.3382 /$ ps.2011-01480

21. Martin CD, Mullens B. Housing and dustbathing effects on northern fowl mites (Ornithonyssus sylviarum) and chicken body lice (Menacanthus stramineus) on hens. Med Vet Entomol. (2012) 26:323-33. doi: 10.1111/j.1365-2915.2011.00997.x

22. Vestergaard KS, Kruijt JP, Hogan JA. Feather pecking and chronic fear in groups of red junglefowl: their relations to dustbathing, rearing environment and social status. Animal Behaviour. (1993) 45:1127-40. doi: 10.1006/anbe.1993.1137

23. Bubier NE. The behavioural priorities of laying hens: the effects of two methods of environment enrichment on time budgets. Behav Proces. (1996) 37:239-49. doi: 10.1016/0376-6357(96)00018-6

24. Bubier NE. The behavioural priorities of laying hens: the effect of cost/no cost multi-choice tests on time budgets. Behav Proces. (1996) 37:22538. doi: 10.1016/0376-6357(96)00019-8

25. Klein $T$, Zeltner E, Huber-Eicher B. Are genetic differences in foraging behaviour of laying hen chicks paralleled by hybridspecific differences in feather pecking? Appl Anim Behav Sci. (2000) 70:143-55. doi: 10.1016/S0168-1591(00)00147-7

26. Inglis IR, Forkman B, Lazarus J. Free food or earned food? A review and fuzzy model of contrafreeloading. Anim Behav. (1997) 53:117191. doi: 10.1006/anbe.1996.0320

27. Duncan IJH, Hughes BO. Free and operant feeding in domestic fowls. Anim Behav. (1972) 20:775-7. doi: 10.1016/S0003-3472(72)80150-7

28. Aerni V, El-Lethey H, Wechsler B. Effect of foraging material and food form on feather pecking in laying hens. Br Poultry Sci. (2000) 41:1621. doi: 10.1080/00071660086349

29. De Jong I, Reuvekamp B, Gunnink H. Can substrate in early rearing prevent feather pecking in adult laying hens? Anim Welf. (2013) 22:30514. doi: 10.7120/09627286.22.3.305

30. Scholz B, Urselmans S, Kjaer J, Schrader L. Food, wood, or plastic as substrates for dustbathing and foraging in laying hens: a preference test. Poultry Sci. (2010) 89:1584-9. doi: 10.3382/ps.2009-00598

31. Fraser D, Matthews LR. Preference and motivation testing. In: Appleby MC, Hughes BO, editors. Animal Welfare. New York, NY: CAB International (1997). p. 159-73.

32. Franks B. What do animals want. Anim Welf. (2019) 28:110. doi: 10.7120/09627286.28.1.001

33. Guinebretière $M$, Beyer $H$, Arnould $C$, Michel V. The choice of litter material to promote pecking, scratching and dustbathing behaviours in laying hens housed in furnished cages. Appl Anim Behav Sci. (2014) 155:5665. doi: 10.1016/j.applanim.2014.02.013

34. Fraser D. Understanding Animal Welfare: The Science in its Cultural Context. Chichester: Wiley-Blackwell (2008).

35. Van Staaveren N, Decina C, Baes CF, Widowski TM, Berke O, HarlanderMatauschek A. A description of laying hen husbandry and management practices in Canada. Animals. (2018) 8:114. doi: 10.3390/ani8070114
36. Mohammed HH, Said EN, Abdel-Hamid SEL. Impact of different litter materials on behaviour, growth performance, feet health and plumage score of Japanese quail (Coturnix japonica). Eur Poultry Sci. (2017) 81:71927. doi: 10.1399/eps.2017.172

37. Rohatgi A. WebPlotDigitizer. 4.2 ed. Pacifica (2015). Available online at: https://automeris.io/WebPlotDigitizer/citation.html

38. Jong ICD, Wolthuis-Fillerup M, Reenen CGv. Strength of preference for dustbathing and foraging substrates in laying hens. Appl Anim Behav Sci. (2007). 104:24-36. doi: 10.1016/j.applanim.2006.04.027

39. Sanotra GS, Vestergaard KS, Agger JF, Lawson LG. The relative preferences for feathers, straw, wood-shavings and sand for dustbathing, pecking and scratching in domestic chicks. Appl Anim Behav Sci. (1995) 43:26377. doi: 10.1016/0168-1591(95)00562-7

40. Shields SJ, Garner JP, Mench JA. Dustbathing by broiler chickens: a comparison of preference for four different substrates. Appl Anim Behav Sci. (2004) 87:69-82. doi: 10.1016/j.applanim.2004.01.003

41. Villagra A, Olivas I, Althaus RL, Gomez EA, Lainez M, Torres AG. Behavior of broiler chickens in four different substrates: a choice test. Brazil J Poultry Sci. (2014) 16:67-75. doi: 10.1590/S1516-635X2014000100010

42. Shields SJ, Garner JP, Mench JA. Effect of sand and wood-shavings bedding on the behavior of broiler chickens. Poultry Sci. (2005) 84:181624. doi: $10.1093 / \mathrm{ps} / 84.12 .1816$

43. Toghyani M, Gheisari A, Modaresi M, Tabeidian SA, Toghyani M. Effect of different litter material on performance and behavior of broiler chickens. Appl Anim Behav Sci. (2010) 122:48-52. doi: 10.1016/j.applanim.2009.11.008

44. van Liere DW, Kooijman J, Wiepkema PR. Dustbathing behaviour of laying hens as related to quality of dustbathing material. Appl Anim Behav Sci. (1990) 26:127-41. doi: 10.1016/0168-1591(90)90093-S

45. Hogan JA, Vestergaard K. The development of a behavior system: dustbathing in the Burmese red junglefowl. III. Effects of experience on stimulus preference. Behaviour. (1992) 121:215-30. doi: 10.1163/156853992X00372

46. Petherick JC, Duncan IJH. Behaviour of young domestic fowl directed towards different substrates. Br Poultry Sci. (1989) 30:229-38. doi: 10.1080/00071668908417143

47. St-Pierre N. Invited review: Integrating quantitative findings from multiple studies using mixed model methodology. J Dairy Sci. (2001) 84:74155. doi: 10.3168/jds.S0022-0302(01)74530-4

48. Sauvant D, Schmidely P, Daudin J-J, St-Pierre NR. Meta-analyses of experimental data in animal nutrition. Animal Int J Anim Biosci. (2008) 2:1203. doi: 10.1017/S1751731108002280

49. Sauvant D, Letourneau-Montminy MP, Schmidely P, Boval M, Loncke C, Daniel JB. Review: use and misuse of meta-analysis in animal science. Animal. (2020) 14:207-s22. doi: 10.1017/S1751731120001688

50. Bibby J, Toutenburg H. Prediction and Improved Estimation in Linear Models. Chichester: Wiley (1977).

51. Lawrence I, Lin K. A concordance correlation coefficient to evaluate reproducibility. Biometrics. (1989) 45:255-68. doi: 10.2307/25 32051

52. Pokharel B. The Impact of Excreta/Excreta Gas Control Strategies on the Behaviour and Physiology of Laying Hens. University of Guelph Department of Animal Biosciences (2019).

53. Monckton V, Van Staaveren N, Harlander-Matauschek A. Broiler chicks' motivation for different wood beddings and amounts of soiling. Animals. (2020) 10:1039. doi: 10.3390/ani10061039

54. Monckton V, Van Staaveren N, Baes CF, Balzani A, HarlanderMatauschek A. Are turkeys (Meleagris gallopavo) motivated to avoid excreta-soiled substrate? Animals. (2020) 10:2015. doi: 10.3390/ani101 12015

55. Pesonen M, Suuronen K, Suomela S, Aalto-Korte K. Occupational allergic contact dermatitis caused by colophonium. Contact Dermat. (2019) 80:917. doi: $10.1111 /$ cod.13114

56. Estlander T, Jolanki R, Alanko K, Kanerva L. Occupational allergic contact dermatitis caused by wood dusts. Contact Dermat. (2001) 44:2137. doi: 10.1034/j.1600-0536.2001.044004213.x

57. Pettit-Riley R, Estevez I. Effects of density on perching behavior of broiler chickens. Appl Anim Behav Sci. (2001) 71:12740. doi: 10.1016/S0168-1591(00)00174-X 
58. Weeks C, Danbury T, Davies H, Hunt P, Kestin S. The behaviour of broiler chickens and its modification by lameness. Appl Anim Behav Sci. (2000) 67:111-25. doi: 10.1016/S0168-1591(99)00102-1

59. Baxter M, Bailie CL, O'Connell NE. An evaluation of potential dustbathing substrates for commercial broiler chickens. Animal. (2018) 12:193341. doi: 10.1017/S1751731117003408

60. Van Liere DW, Bokma S. Short-term feather maintenance as a function of dust-bathing in laying hens. Appl Anim Behav Sci. (1987) 18:197204. doi: 10.1016/0168-1591(87)90193-6

61. Pokharel B, Boecker I, Kwon I, Jeyachanthiran L, McBride P, HarlanderMatauschek A. How does the presence of excreta affect the behavior of laying hens on scratch pads? Poultry Sci. (2018) 97:743-8. doi: 10.3382/ps/pex375

62. Von Waldburg-Zeil C, van Staaveren N, Harlander-Matauschek A. Do laying hens eat and forage in excreta from other hens? Animal. (2019) 13:36773. doi: $10.1017 /$ S1751731118001143

63. Hörnicke H, Björhag G, editors. Digestive physiology and metabolism in ruminants. In: Coprophagy and Related Strategies for Digesta Utilization 5th International-Symposium on Ruminant Physiology. Clermont-Ferrand: Annales De Recherches Veterinaires (1979). doi: 10.1007/978-94-011-8067-2_34
64. Moesta A, Knierim U, Briese A, Hartung J. The effect of litter condition and depth on the suitability of wood shavings for dustbathing behaviour. Appl Anim Behav Sci. (2008) 115:160-70. doi: 10.1016/j.applanim.2008.06.005

65. Koroshetz WJ, Behrman S, Brame CJ, Branchaw JL, Brown EN, Clark EA, et al. Research culture: framework for advancing rigorous research. Elife. (2020) 9:e55915. doi: 10.7554/eLife.55915

66. Tannenbaum J, Bennett BT. Russell and Burch's 3Rs then and now: the need for clarity in definition and purpose. J Am Assoc Lab Anim Sci. (2015) 54:120-32.

Conflict of Interest: The authors declare that the research was conducted in the absence of any commercial or financial relationships that could be construed as a potential conflict of interest.

Copyright (C) 2020 Monckton, Ellis and Harlander-Matauschek. This is an openaccess article distributed under the terms of the Creative Commons Attribution License (CC BY). The use, distribution or reproduction in other forums is permitted, provided the original author(s) and the copyright owner(s) are credited and that the original publication in this journal is cited, in accordance with accepted academic practice. No use, distribution or reproduction is permitted which does not comply with these terms. 